\title{
Interlaminar crack propagation in MWCNT/fiber reinforced hybrid composites
}

\author{
G. Romhány*, G. Szebényi \\ Department of Polymer Engineering, Budapest University of Technology and Economics, Múegyetem rkp. 3., \\ H-1111 Budapest, Hungary
}

Received 21 December 2008; accepted in revised form 30 January 2009

\begin{abstract}
In this work carbon fiber/epoxy composites and MWCNT (multiwalled carbon nanotube)/carbon fiber/epoxy hybrid composites with $0.1,0.3,0.5$ and 1 weight $\%$ nanotube filling of the matrix have been prepared and compared in terms of interlaminar properties. For the dispersion of the carbon nanotubes in the epoxy resin three roll milling has been utilized. The mechanical characterization has been carried out using standard DCB (double cantilever beam) tests assisted by acoustic emission. The test results have been evaluated by the conventional method provided by the standard and a novel method implementing acoustic emission signal localization for crack propagation tracing. According to the tests carbon nanotube filling of the matrix of the composites has a beneficial effect on their interlaminar properties: the interlaminar fracture toughness values of the composites have increased by a maximum of 13 and $33 \%$ at a 0.3 weight $\%$ carbon nanotube content of the matrix according to the conventional and AE based evaluation method respectively.
\end{abstract}

Keywords: polymer composites, nanocomposites, material testing, acoustic emission

\section{Introduction}

In their first decades fiber reinforced composites mainly played the role of high performance materials for the high-tech industries as aerospace, military and racing industries. Nowadays the need for more fuel efficient vehicles in both aviation and vehicular traffic has induced the coming of a second golden age for composite materials. In most of their applications the composite parts are subjected to vibration which could lead to delamination and thereby the failure of the part, so it is crucial to improve the delamination resistance of polymer matrix composite materials.

Multiple reports showed the positive effect of carbon nanotube filling on the crack propagation resistance of polymer resins [1, 2]. Gojny et al. [3] have tested a standard epoxy resin mainly used for resin infusion filled with functionalized and unfunctionalized nanotubes. According to their tests a $43 \%$ increase in the fracture toughness of the resin could be observed at a $0,5 \%$ loading of amine functionalized DWCNTs (double walled carbon nanotubes). Ganguli et al. [4] examined the effect of MWCNT filling on the fracture toughness of a tetrafunctional epoxy resin through single edge notch three-point bending tests. They have measured a three-fold increase in the stress intensity factor at 1 weight $\%$ MWCNT loading. Delamination occurs in the resin filled interlayer between the reinforcement material layers in composite structures, so any toughening of the matrix material can improve delamination resistance. Although some promising theoretical results [5] and improvements in other interlaminar properties like interlaminar shear strength $[6,7]$ have been reported, few publications provide direct data on the interlaminar crack 
propagation in CNT (carbon nanaotube) and fiber reinforced hybrid composites. Wichmann et al. [8] have reported a decrease in the Mode I interlaminar fracture toughness of DWCNT and glass fiber reinforced epoxy matrix composites, and pointed some difficulties during the tests caused by the obstructed tracking of the crack tip in the opaque resin using the conventional visual crack tracking during DCB testing. In our previous studies we have reported some indirect delamination resistance improvement in a nanotube/fiber reinforced system [9]. The aim of this research is to directly characterize the effect of carbon nanotube filling on the interlaminar mechanical properties of fiber reinforced composites through standard DCB tests.

\section{Experimental}

\subsection{Materials}

FM-20 epoxy laminating resin was used $(\mathrm{P}+\mathrm{M}$ Polimerkémia Kft., Hungary) with T-16 curing agent ( $\mathrm{P}+\mathrm{M}$ Polimerkémia Kft., Hungary) as matrix. The recommended mixing weight ratio was 100:20, the resin had a curing treatment of $4 \mathrm{~h}$ at $60^{\circ} \mathrm{C}$.

Baytubes ${ }^{\circledR}$ BT150 HP (Bayer, Germany) multiwalled carbon nanotubes (MWCNTs) were used as filler in one portion of the matrix (Figure 1). The nanotubes have been produced in a CVD based catalytic process resulting in an average outer diameter between 13-16 nm, length above $1 \mu \mathrm{m}$ and carbon purity above $99 \%$ according to the manufacturer. The carbon nanotubes have been mixed to the epoxy component of the resin using a three roll mill, four pass-throughs have been carried out to

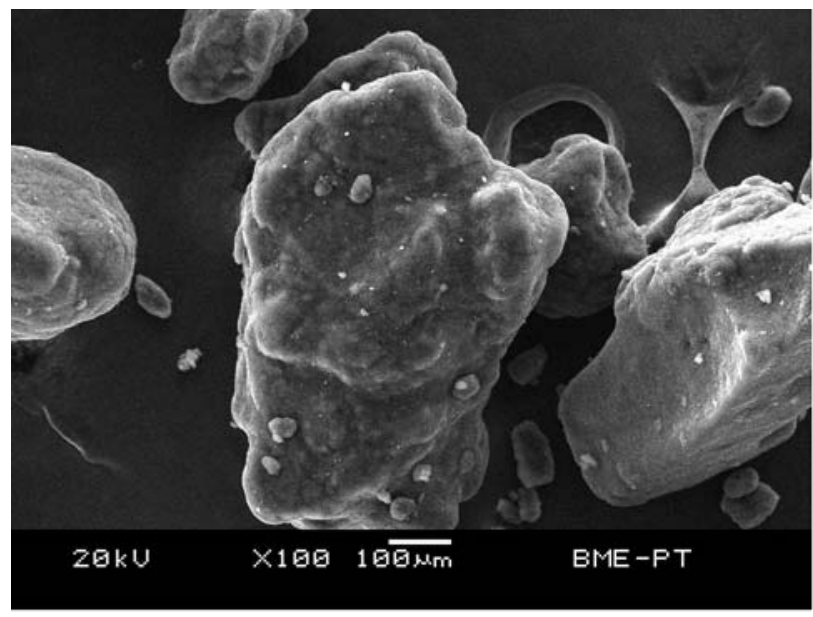

a) achieve uniform dispersion and appropriate particle size $(<10 \mu \mathrm{m})$.

Zoltek PX35FBUD0300 unidirectional carbon fabric (Zoltek Ltd., Hungary) has been used as fiber reinforcement in the composites. The fabric consisted of 50k rovings, and had a surface weight of $300 \mathrm{~g} / \mathrm{m}^{2}$.

\subsection{Composite preparation}

To characterize the effect of the nanotube filling of the matrix on the properties of carbon fiber reinforced composites one carbon fiber/epoxy laminate and four carbon nanotube/carbon fiber/epoxy laminates with $0.1,0.3,0.5$, and 1 weight $\%$ nanotube filling have been produced under the same circumstances.

The laminates have been produced by hand lamination of 10 plies of carbon fabric impregnated with the resin, the fiber orientation of all laminae has been $0^{\circ}$. A $50 \mu \mathrm{m}$ thick PET film has been used as a delamination initiator insert in the center plane (between the $5^{\text {th }}$ and $6^{\text {th }}$ lamina) of the laminates. Both sides of the film have been coated with mould release agent to minimize adhesion between the film and the matrix of the composite. To avoid trapped in air bubbles, the laminate has been rolled after every two plies.

To achieve uniform thickness and fiber content the laminate has been pressed for 12 hours under $30 \mathrm{kN}$ at room temperature. The uniform thickness of all of the laminates has been achieved by using a $4 \mathrm{~mm}$ thick steel plate placed as a spreader next to the laminates in the press. The fiber contents were $49.2 \pm 1.1, \quad 51.9 \pm 2.8, \quad 51.7 \pm 3.2, \quad 51.9 \pm 2.7$, and

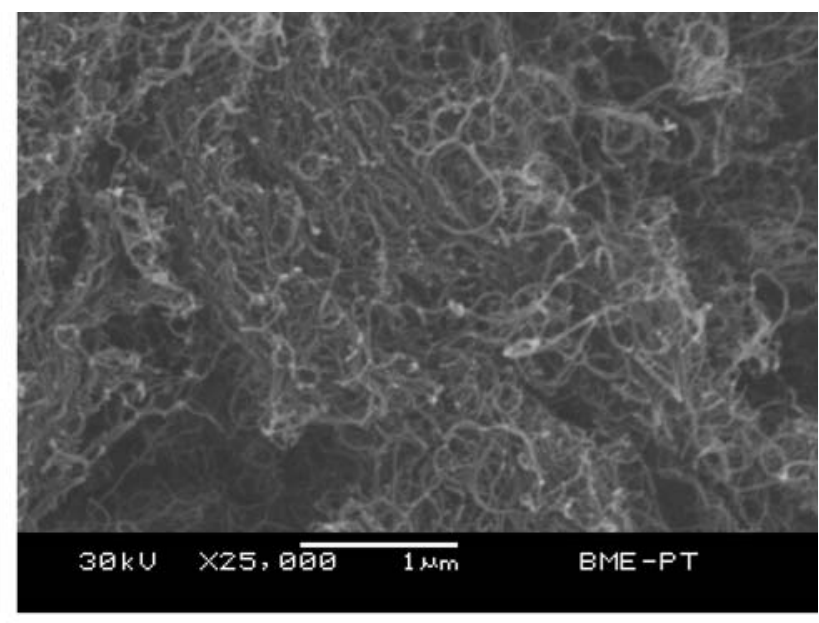

b)

Figure 1. SEM micrographs of the MWCNT aggregates (a) and MWCNTs (b) used (raw materials) 
$53.4 \pm 1.9$ volume $\%$ in the unfilled and $0.1,0.3,0.5$ and 1 weight $\%$ MWCNT filled composite respectively.

\subsection{Specimen preparation}

8 specimens have been cut out of each laminate parallel to the fiber orientation according to ASTM D 5528 - 01 with a length of $210 \mathrm{~mm}$, width of $25 \mathrm{~mm}$, thickness of $4 \mathrm{~mm}$, and an insert length of $65 \mathrm{~mm}$. The edges of each specimen have been coated just ahead of the insert with a thin layer of water-based typewriter correction fluid to aid the visual detection of delamination propagation. A $100 \mathrm{~mm}$ length of the specimens has been marked with thin vertical lines every $2 \mathrm{~mm}$ from the insert to help the recording of the crack front position.

Steel load hinges have been mounted on the top and the bottom of each specimen using Sikadur 330 (Sika, Germany) adhesive, special care has been taken to the correct positioning of the load blocks. The specimen and test setup can be seen in Figure 2.

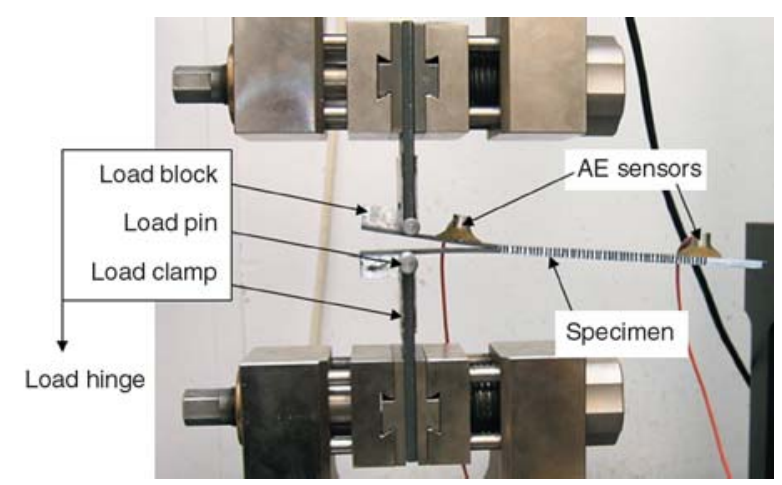

Figure 2. The DCB test setup

\subsection{Characterization}

Mode I interlaminar fracture toughness tests have been carried out on the test specimens according to ASTM D $5528-01$ at a test speed of $5 \mathrm{~mm} / \mathrm{min}$ using a Zwick 005 universal, computer controlled testing machine.

To pinpoint the position of the crack propagation more accurately than in case of visual detection the acoustic emission (AE) technique $[10,11]$ has been used (during visual detection, the crack propagation can only be observed after the curved crack front has reached the edge of the specimen, while $\mathrm{AE}$ signals can be detected immediately after the crack
Detection time difference: $\Delta t$ Distance between sensors: $d$ $A E$ signal speed: $v \quad$ Position of $A E$ signal source: $x=(d-v \cdot \Delta t) / 2$

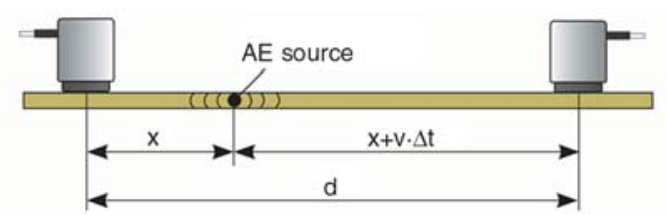

Figure 3. The principles of the localization of an $\mathrm{AE}$ source

front starts to form). Sensophone AED-40 device with Physical Acoustics Corporation Micro30S sensors in the frequency range from 100 to $600 \mathrm{kHz}$ have been used. Logarithmic amplifying has been applied. The threshold has been set to $30 \mathrm{~dB}$ to filter out ambient noises, and the reference voltage of the test device has been $3 \mathrm{mV}$. Two AE sensors have been fixed on the surface of the specimens at given positions, $120 \mathrm{~mm}$-s from each other. After the measurement of the speed of AE signal propagation in the specimens $(9000 \mathrm{~m} / \mathrm{s})$, the exact location of the $\mathrm{AE}$ event source, and so the crack front could be calculated from the detection time difference of the two sensors (Figure 3).

\section{Results and discussion}

The main results of the DCB tests are the force load point displacement and the crack front position - time curves. From these curves and the specimen geometry data the crack front position interlaminar fracture toughness curves can be calculated and composed. The calculation of the strain energy release rate has been carried out using the modified beam theory. For the evaluation of the critical interlaminar fracture toughness, the $5 \%$ offset/maximum load method of the standard has been chosen. This method is the most effective to exclude the subjectivity of visual crack front tracing, but it has no direct connection with the failure processes in the specimens.

The critical interlaminar toughness values provided by this method can be observed in Figure 4. From the results it can be said that the $G_{I c}$ values increase with nanotube content to 0.3 weight $\%$ filling, after that a decrease can be observed. At 0.3 weight $\%$ nanotube content a $13 \%$ increase could be measured in the average toughness values compared to the unfilled matrix specimens. 


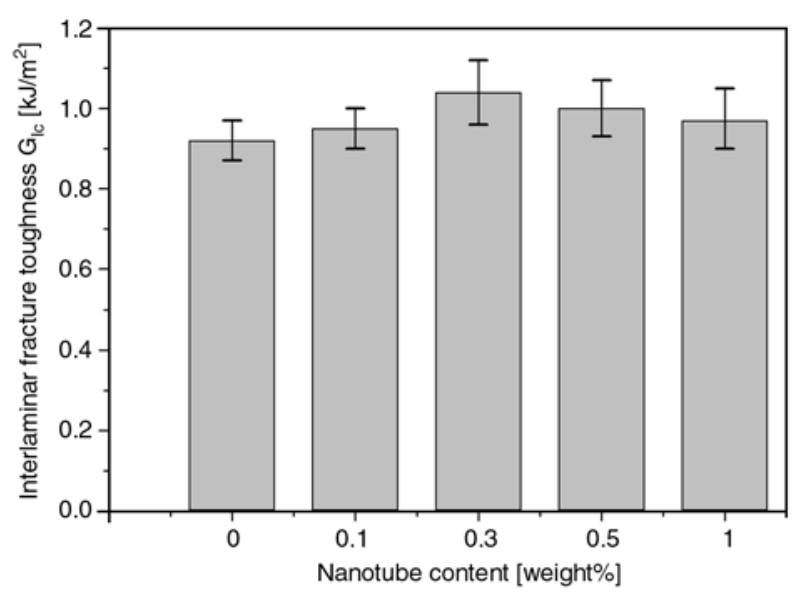

Figure 4. Interlaminar fracture toughness values of the composites and hybrid composites obtained by the $5 \%$ deviation method

The aim of using the AE technique was to introduce a crack propagation start criteria fully free of subjectivity, and in direct connection with the actual start of crack propagation.

The crack position values of $\mathrm{AE}$ events localized during the testing of a 0.1 weight $\%$ nanotube filled specimen can be seen in Figure 5.

From the graph it can be clearly seen that a dense region is present, containing a most of the detected AE signals, but the full spectrum is covered with traces. It can be explained firstly by the vast amount of $\mathrm{AE}$ events, leading to some localization problems (the device could not match all detection time differences with the right signal), secondly by the reflection of the AE signals in the specimens, which can make localization more difficult. In case of a high amplitude AE signal there is a high probability that it is a primary signal (signal detected for the first time, directly after emitted by the source), not a

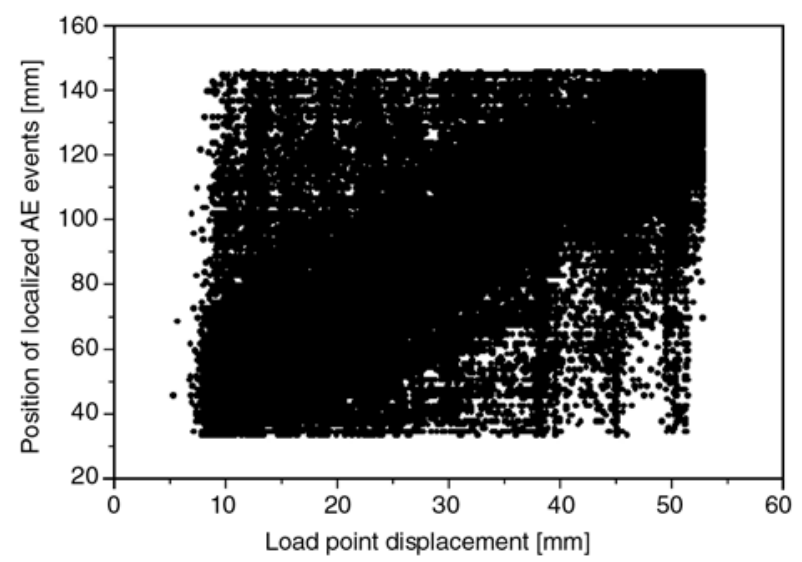

Figure 5. The localized AE events of a hybrid composite specimen with 0.1 weight $\%$ MWCNT content reflection. Therefore to filter improperly localized signals an amplitude threshold has been set.

After plotting the amplitudes of all localized events, this threshold has been set at $60 \mathrm{~dB}$. Above this level higher amplitude signals could be still continually detected.

The events remaining after the filtering are plotted in Figure 6. It can be observed, that the region of the events representing the propagation of the crack front could be successfully narrowed down, also a clear trend can be observed according to the propagation of the crack front.

The results could be refined further by calculating the average of the crack positions in $15 \mathrm{~s}$ long intervals (1.25 mm of load point displacement). In Figure 7 the so calculated crack tip positions and the visually recorded positions can be compared. The crack tip positions are close to each other, so the AE localization could be verified by the visually recorded data.

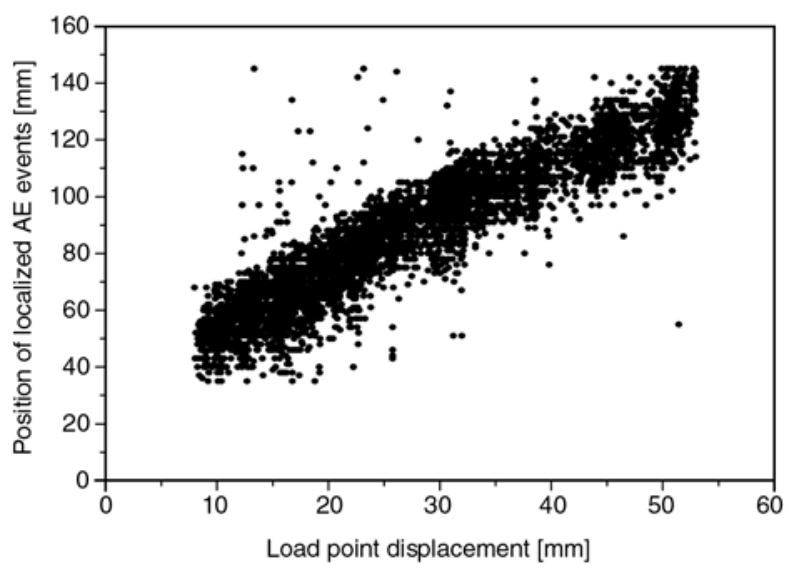

Figure 6. The localized AE events of a hybrid composite specimen with 0.1 weight $\%$ MWCNT content after filtering

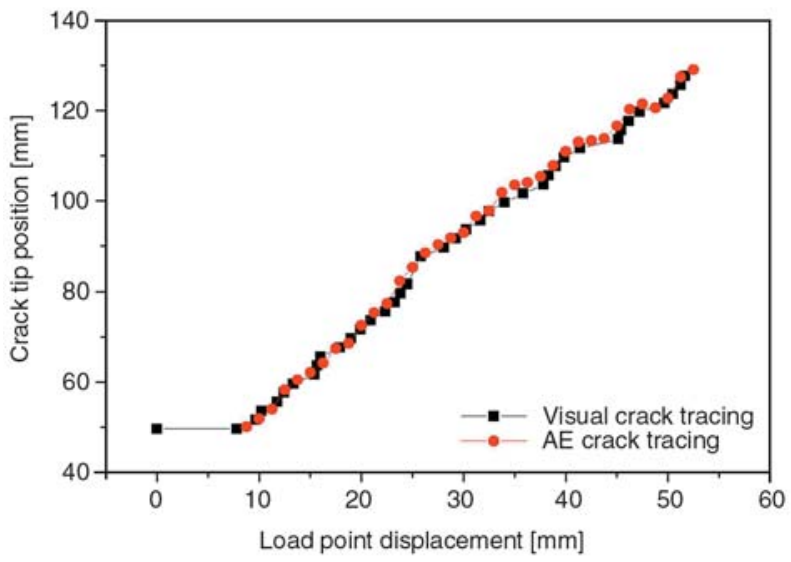

Figure 7. Comparison of crack tracing methods by a hybrid composite specimen with 0.1 weight $\%$ MWCNT 


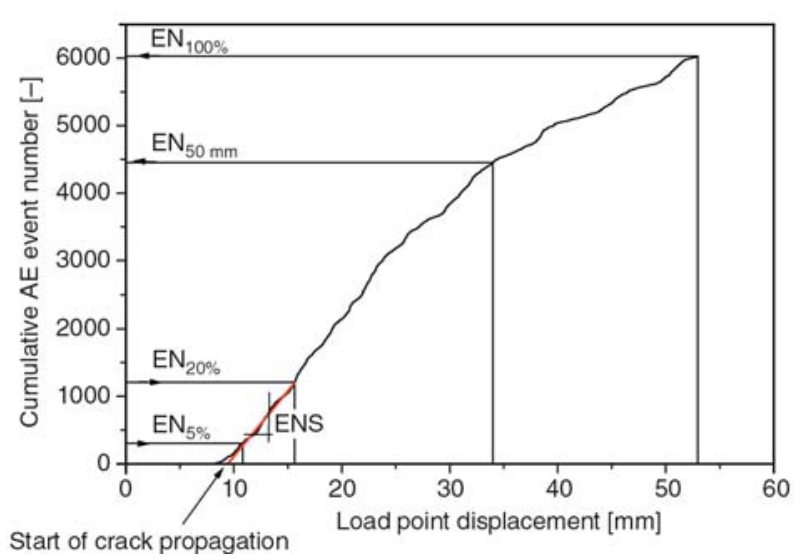

Figure 8. The definition of crack propagation start for the AE technique

In Figure 8 the cumulative $\mathrm{AE}$ event number versus load point displacement plot can be seen. It can be observed, that initially no signal is detected, then after a short transient section the acoustic activity and the slope of the curve increase significantly. It is evident that the crack propagation starts in the transient section. The crack propagation start has been defined as follows. The points corresponding to the 5 and $20 \%$ of total event number have been determined, and after that a line has been fitted between these two points using linear regression. The intersection of the regression line and the $x$ axis has been defined as the opening displacement where the crack propagation started. The $G_{I c}$ values calculated using these data are plotted in Figure 9.

Compared to the method described in the standard the tendency of the $G_{I c}$ values in function of carbon nanotube content is the same, but in the values there is a significant difference. The difference can be explained by the more accurate crack tracing

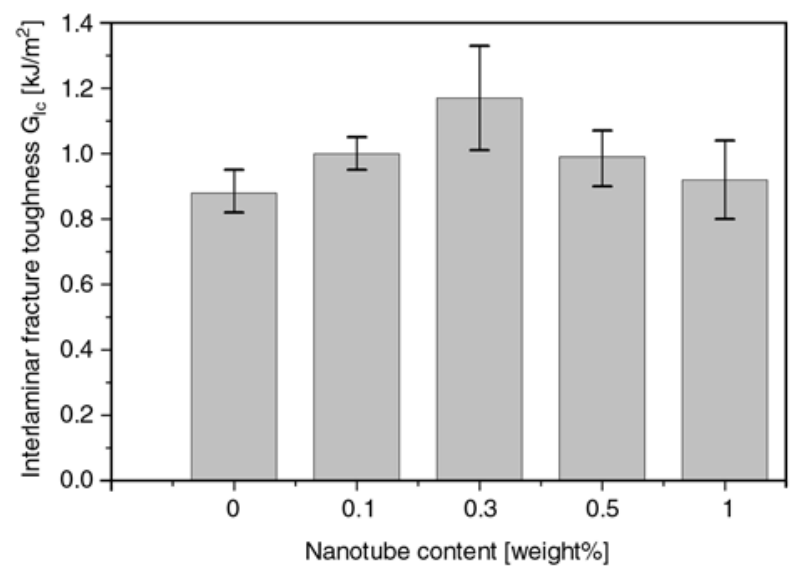

Figure 9. Interlaminar fracture toughness values of the composites and hybrid composites obtained by the AE method

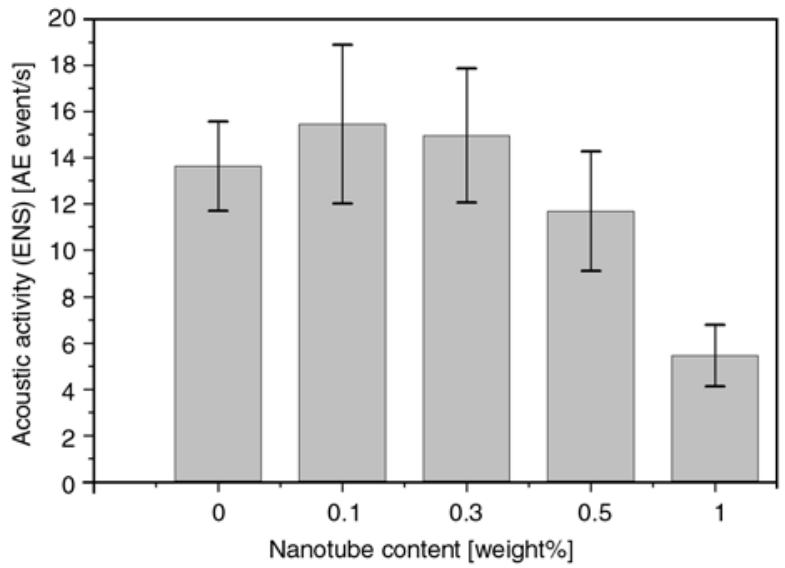

Figure 10. Acoustic activity as a function of nanotube content

method, the crack propagation start could be pinpointed more precisely using the $\mathrm{AE}$ technique.

The slope of the line, fitted between the $\mathrm{EN}_{5 \%}$ and $\mathrm{EN}_{20 \%}$ points of the cumulative $\mathrm{AE}$ event number curve (ENS in Figure 8.), which corresponds to the acoustic activity during the stage of crack propagation (Figure 10), and also the event number localized till $50 \mathrm{~mm}$ crack propagation have been calculated (Figure 11).

The tendencies of both the acoustic activity and the event number versus carbon nanotube content are similar to the tendency of $G_{I c}$. The event number values and the initial increase in acoustic activity suggest that the crack propagation can be composed of multiple smaller cracks. In case of brittle materials, like the epoxy used, unstable crack propagation can be observed, because the energy released during crack propagation is higher, than the energy needed for the creation of free surfaces. The crack front advances through unstably jumping

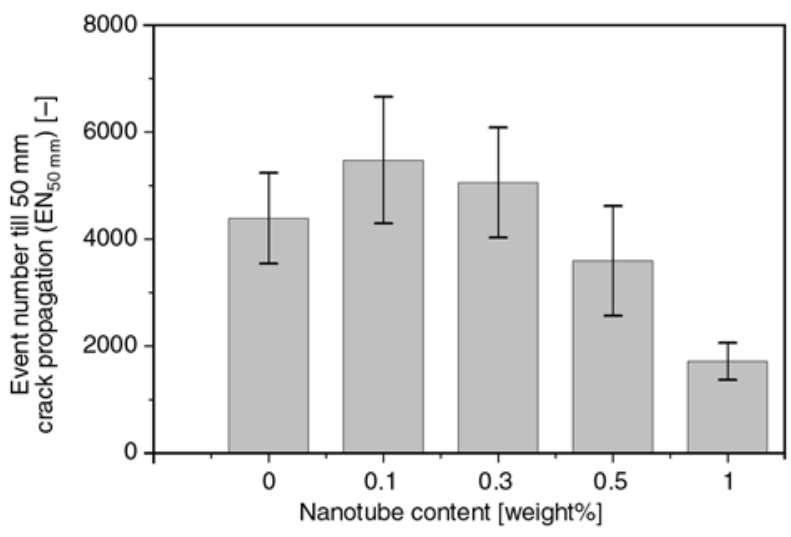

Figure 11. AE events localized till $50 \mathrm{~mm}$ crack propagation 
and stopping microcracks, as with the advancement of the crack, the stress in the crack front is decreasing, and the crack propagation is caused by further opening displacement. The adhesion between the matrix and the nanotubes is fairly weak, so the nanotubes function as nanosized continuity flaws in the matrix in this case. When the microcracks jump forward, they propagate unstably, and when they reach a continuity flaw provided by a nanotube, they are pinned, so compared to the unfilled matrix composite, in hybrid composites, the formation of a higher amount, but smaller sized microcracks can be suggested. This causes the increase in acoustic event number and activity. According to the event numbers, above $0.5 \%$ nanotube filling another failure mechanism dominates. In that case nanotubes are present in such high amounts, that they tend to contact and form larger impurities, which have still the chance of pinning the microcracks, but they reduce the effective length of matrix material, which the crack has to propagate through which leads to less AE events, and lower resistance against crack propagation.

It is worthwhile to compare not only the $G_{I c}$ values, representing only one point of crack propagation, but also the full strain energy rate - crack length increase curves to get a deeper understanding of the full failure process, especially after $G_{I c}$. The $R$ curves obtained from the averaging of the curves of each specimen of same nanotube contents can be observed in Figures 12 and 13. It can be clearly seen that the hybrid systems containing 0.1 and 0.3 weight $\%$ carbon nanotubes significantly outperform the unfilled matrix composite, while the 0.5 and 1 weight $\%$ nanotube filled ones remain around the level of the unfilled specimens.

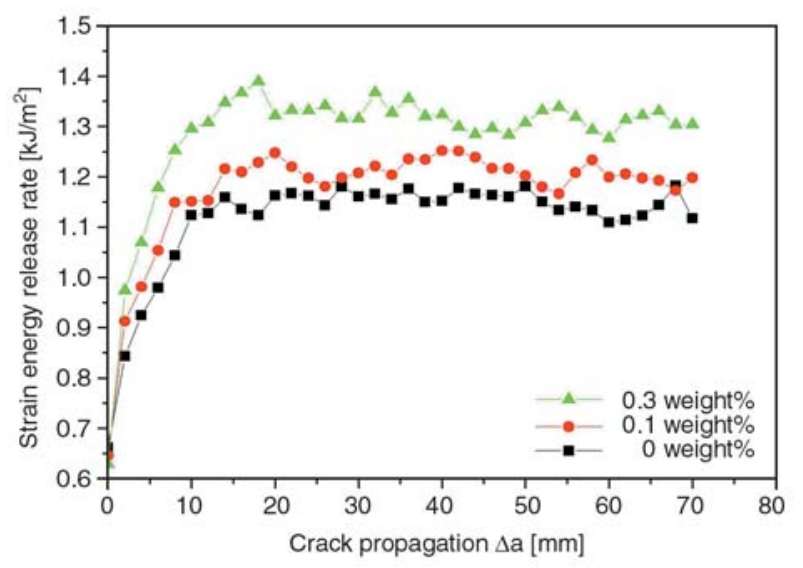

Figure 12. Average $R$-curves for composites containing 0, 0.1 and 0.3 weight $\%$ MWCNTs

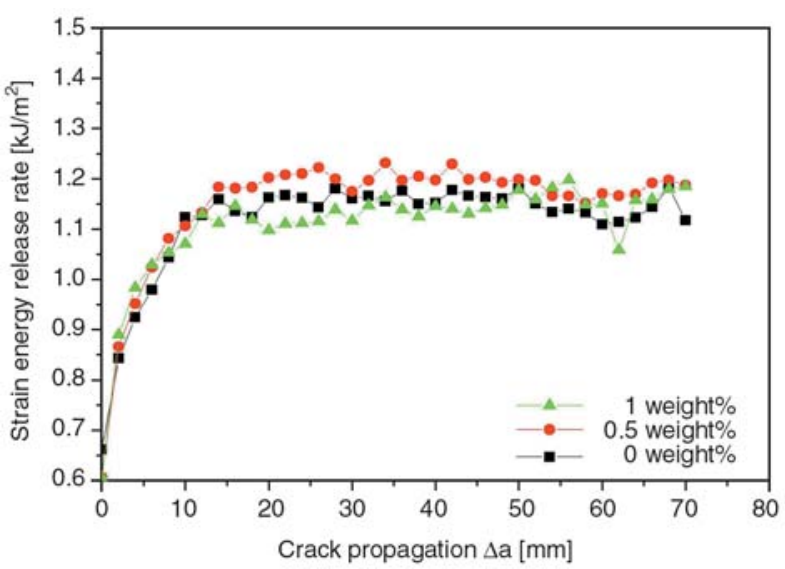

Figure 13. Average $R$-curves for composites containing $0,0.5$ and 1 weight $\%$ MWCNTs

\section{Conclusions}

In this work the effect of MWCNT reinforcement on the interlaminar mechanical properties of conventional carbon fiber/epoxy composites has been studied. The dispersion of the carbon nanotubes in the epoxy resin has been carried out using easily upscalable technique, three roll milling. Hybrid composite laminates containing $0,0.1,0.3,0.5$ and 1 weight $\%$ MWCNT filled matrices have been prepared by hand lamination followed by pressing using the nanotube filled resin and unidirectional carbon fabric. The mechanical characterization has been carried out using standard DCB tests assisted by acoustic emission. During the testing the negative effect of the completely opaque nanotube filled resin on the visual crack propagation tracing has been disabled using a novel evaluation technique utilizing AE crack tracing. According to the tests carbon nanotube filling of the matrix of the composites has a beneficial effect on their interlaminar properties: the interlaminar fracture toughness values of the composites have increased by a maximum of 13 and $33 \%$ at a 0.3 weight $\%$ carbon nanotube content of the matrix according to the conventional and $\mathrm{AE}$ based evaluation method respectively. According to our results it can be declared, that carbon nanotube filling of the matrix of conventional fiber reinforced composites can increase their performance, reliability when subjected to the danger of delamination. 


\section{Acknowledgements}

The authors would like to sincerely thank Bayer Hungaria Ltd. and Bayer MaterialScience AG. for the donation of the Baytubes $^{\circledR}$. This work was supported by the Hungarian Scientific Research Fund (OTKA F67897 and NI62729) and János Bolyai Research Scholarship of the Hungarian Academy of Sciences.

\section{References}

[1] Du J-H., Bai J., Cheng H-M.: The present status and key problems of carbon nanotube based polymer composites. Express Polymer Letters, 1, 253-273 (2007). DOI: $10.3144 /$ expresspolymlett.2007.39

[2] Zhou Y. X., Wu P. X., Cheng Z-Y., Ingram J., Jeelani S.: Improvement in electrical, thermal and mechanical properties of epoxy by filling carbon nanotube. Express Polymer Letters, 2, 40-48 (2008). DOI: $10.3144 /$ expresspolymlett.2008.6

[3] Gojny F. H., Wichmann M. H. G., Fiedler B., Schulte K.: Influence of different carbon nanotubes on the mechanical properties of epoxy matrix composites A comparative study. Composites Science and Technology, 65, 2300-2313 (2005).

DOI: 10.1016/j.compscitech.2005.04.021

[4] Ganguli S., Bhuyan M., Allie L., Aglan H.: Effect of multi-walled carbon nanotube reinforcement on the fracture behavior of a tetrafunctional epoxy. Journal of Materials Science, 40, 3593-3595 (2005).

DOI: $10.1007 / \mathrm{s} 10853-005-2891-\mathrm{x}$

[5] Tong L., Sun X., Tan P.: Effect of long multi-walled carbon nanotubes on delamination toughness of laminated composites. Journal of Composite Materials, 42, 5-23 (2008).

DOI: $\underline{10.1177 / 0021998307086186}$
[6] Kim M-G., Hong J-S., Kang S-G., Kim C-G.: Enhancement of the crack growth resistance of a carbon/epoxy composite by adding multi-walled carbon nanotubes at a cryogenic temperature. Composites Part A: Applied Science and Manufacturing, 39, 647 654 (2008). DOI: $10.1016 /$ j.compositesa.2007.07.017

[7] Gojny F. H., Wichmann M. H. G., Fiedler B., Bauhofer W., Schulte K.: Influence of nano-modification on the mechanical and electrical properties of conventional fibre-reinforced composites. Composites Part A: Applied Science and Manufacturing, 36, 1525-1535 (2005).

DOI: 10.1016/j.compositesa.2005.02.007

[8] Wichmann M. H. G., Sumfleth J., Gojny F. H., Quaresimin M., Fiedler B., Schulte K.: Glass-fibrereinforced composites with enhanced mechanical and electrical properties- Benefits and limitations of a nanoparticle modified matrix. Engineering Fracture Mechanics, 73, 2346-2359 (2006).

DOI: 10.1016/j.engfracmech.2006.05.015

[9] Romhány G., Szebényi G.: Preparation of MWCNT/ carbon fabric reinforced hybrid nanocomposite and examination of its mechanical properties. Materials Science Forum, 589, 269-274 (2008).

[10] Czigány T., Marosfalvi J., Karger-Kocsis J.: An acoustic emission study of the temperature-dependent fracture behavior of polypropylene composites reinforced by continuous and discontinuous fiber mats. Composites Science and Technology, 60, 1203-1212 (2000). DOI: $10.1016 / \mathrm{S} 0266-3538(00) 00059-2$

[11] Czigány T., Karger-Kocsis J.: Determination of the damage zone size in textile fabric reinforced polypropylene composites by locating the acoustic emission. Polymers and Polymer Composites, 1, 329-339 (1993). 